Cover art:

A soft $X$-ray image of the world's highest beta tokamak plasma is superimposed on measured magnetic flux surfaces. The color snapshot of the $11 \%$ beta DIII-D plasma is generated with computer-aided tomographic Imaging - from a GA-LLNL-ORNL. collaboration (Shot 69605 at 1.415 seconds).

U.S. Department of Energy funds were not used to support color printing for the cover of this report. 
GA-A- -20791

DE9 2010384

\title{
FUSION TECHNOLOGY DEVELOPMENT
}

\author{
ANNUAL REPORT TO THE \\ U.S. DEPARTMENT OF ENERGY
}

OCTOBER 1, 1990 THROUGH SEPTEMBER 30, 1991

\author{
by \\ PROJECT STAFF
}

\author{
Work prepared under \\ Department of Energy \\ Contract DE-AC03-89ER52153
}

GENERAL ATOMICS PROJECT 3469

DATE PUBLISHED: MARCH 1992

MASTER

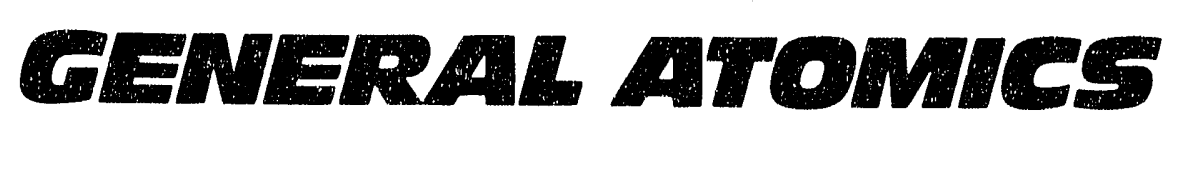




\section{DISCLAIMER}

This report wes prepared as an account of work sponsored by an agency of the United States Government. Neither the United States Government nor any agency thereof, nor any of their employees, makes any warranty, express or implied, or assumes any legal liability or responsibility for the accuracy, completeness, or usefulness of any information, apparatus, product, or process disclosed, or represents that its use would not infringe privately owned rights. Reference herein to any specific commercial product, process, or service by trade name, trademark, manufactures, or otherwise, does not necessarily constitute or imply its endorsement, recommendation, or favoring by the United States Government or any agency thereof. The views and opinions of authors expressed herein do not necessarily state or reflect those of the United States Government or any agency thereof.

This report has been reproduced directly from the best available copy.

Available to DOE and DOE contractors from the Office of Scientific and Technical Information

P.O. Box 62

Oak Ridge, TN 37831

Prices available from (615) 576-8401, FTS 626-8401.

Available to the public from the National Technical Information Service

U.S. Department of Commerce 5285 Port Royal Rd.

Springfield, VA 22161 


\section{TABLE OF CONTENTS}

1. DEVELOPMENT AND TECHNOLOGY OVERVIEW ........................... 1-1

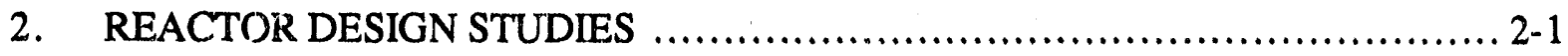

2.1. Overview and R\&D Needs ........................................... 2-1

2.2. Project Directions .................................................. 2-1

2.3. Engineering Innovations/Fusion Power Core Design ..................... 2-2

2.3.1. ARIES-III Design ........................................... 2-2

2.3.2. ARIES-II and IV Designs .................................... 2-3

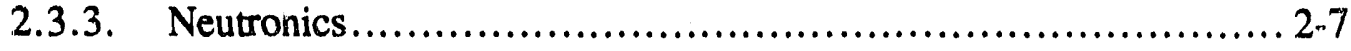

2.3.4. Physics .................................................. 2-7

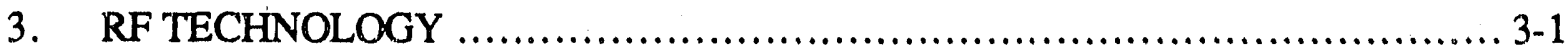

4. FUSION NUCLEAR TECHNOLOGIES ..................................... 4-1

5. PLASMA FACING COMPONENTS ....................................... 5-1

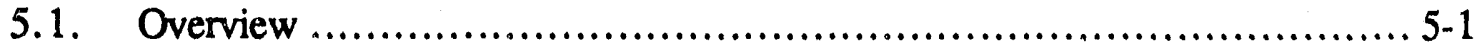

5.2. Project Directions ...................................................... 5-1

5.3. Integral Exposure Experiment ...................................... 5-2

5.4. DIMES Sample Changer System ..................................... 5-2

5.5. Visiting Scientist .................................................... 5

6. FY91 PUBLICATIONS ........................................................... 6-1

GA-A20791; FY91 Fusion Technology Development Annual Report iii 


\section{LIST OF FIGURES}

2.3-1. Divertor and blanket sector ................................................ 2-4

2.3-2. He-cooled SiC-composite sector details ....................................... 2-5

2.3-3. He-cooled SiC-composite divertor unit-cell ................................... 2-6 
SECTION 1 DEVELOPMENT AND TECHNOLOGY OVERVIEW 


\section{DEVELOPMENT AND TECHNOLOGY OVERVIEW}

In FY91, the General Atomics Fusion Group made significant contributions to the technology needs of the controlled fusion power program. The work was supported by the Office of Fusion Energy, Development and Technology Division, of the U.S. Department of Energy. These studies included work on Reactor Studies, RF Technology, Fusion Nuclear Technology, and Plasma Facing Components.

The efforts by General Atomics (GA) are based on the recognition that the implementation of controlled fusion as a major energy source requires significant technology developrnent. This is needed to support both near-term experimental efforts and the eventual fusion reactors. We continue to be committed to the development of fusion power and its commercialization by the U.S. industry. 
SECTION 2 REACTOR DESIGN STUDIES 


\section{REACTOR DESIGN STUDIES}

\subsection{OVERVIEW AND R\&D NEEDS}

The goal of reactor design studies is to provide critical assessment of the projected performance of fusion experiments, reactors, systems and components; to develop potential solutions to the key technical problems uncovered in these assessments; and to offer recommendations for fusion research and development that could help resolve these problems and lead to improved fusion system performance. This activity helps to define the goals and $R \& D$ needs of the fusion program, and thus adds focus to near-term activities.

During FY91, GA continued to play a lead role in the Advanced Reactor Innovations Evaluation Study (ARIES) directed by Prof. Robert Conn of UCLA. This is the fourth year of a five-year study focused on different advanced embodiments of tokamak reactor design, with emphasis on innovation, attractiveness, safety, and economics. Within the ARIES project, GA is responsible for the project operation, with Dr. Kenneth Schultz acting as the Deputy Project Director for Operation. We are supporting the design, analysis, and evaluation of high performance fusion power core components such as divertors, first walls, blankets and shields, including detailed neutronics evaluations and safety designs. We also are continuing to provide senior plasma physics personnel to integrate the latest tokamak experimental results into the ARIES study.

\subsection{PROJECT DIRECTIONS}

The ARIES study will develop four different "visions" of a fusion power reactor based on the tokamak concept. During the first-year scoping phase of ARIES from 1988 through February 1989, we identified the major characteristics of the visions. During the second year, we developed a more detailed conceptual design of the first vision. During the third year, we completed the first ARIES design and initiated the socond and third ARIES designs. During the fourth year we completed the ARIES-III design and continued on the ARIES-II and IV designs. 
The ARIES-I design assumes a minimum extrapolation in physics and, hence, is close to the present tokamak database (e.g., ARIES-I operates in the first MHD stability regime.) The ARIES-I reactor incorporates technologies that would be available over the next 20 to 30 years given the current knowledge of these technologies within and outside the fusion program. The ARIES-I reactor is a $1000 \mathrm{MWe}$ (net) reactor with a plasma major radius of $6.75 \mathrm{~m}$, a minor radius of $1.5 \mathrm{~m}$, and a neutron wall loading of $2.5 \mathrm{MW} / \mathrm{m}^{2}$. It has an aspect ratio of 4.5 and a magnetic field of $21 \mathrm{~T}$ at the coil. The ARIES-I blanket is cooled by He and consists of SiCcomposite structural material, $\mathrm{Li}_{2} \mathrm{ZrO}_{3}$ solid breeder, and $\mathrm{Be}$ neutron multiplier.

During FY90, we initialed the ARIES-II design, which assumes the improved physics performance of the MHD "second stability regime" in order to achieve a more attractive reactor. However, DOE asked the ARIES team to help provide NASA with information to help them in their evaluation of the importance of the ${ }^{3} \mathrm{He}$ resource available on the moon. Accordingly, we have deferred work on ARIES-II and have been working on the ARIES-III D- ${ }^{3} \mathrm{He}$ advanced fuel design. This design study allows advances in both physics and technology and seeks to develop a concept that will allow the low neutron yield $\mathrm{D}-{ }^{3} \mathrm{He}$ reaction to be most effectively utilized in a tokamak power reactor. During FY91, we completed the ARIES-III D- ${ }^{3} \mathrm{He}$ advanced fuel design. The reference ARIES-III design has an aspect ratio of 3 and operates in the second MHD stability regime. We then continued on to the evaluation and selection of the ARIES II and IV designs.

\subsection{ENGINEERING INNOVATIONS/FUSION POWER CORE DESIGN}

During FY91, we continued the design support of the ARIES-III organic coolant (OC)cooled reactor design and evaluated the helium-cooled, SiC composite, closed cycle gas turbine design. GA was in charge of coordinating the $\mathrm{OC}$-cooled divertor system design, and evaluated the helium-cooled divertor design. We also were active in the design and evaluation of the ARIES-II and IV designs.

\subsubsection{ARIES-III DESIGN}

Due to the power balance requirement of the plasma burn, the first wall of the $\mathrm{D}^{-3} \mathrm{He}$ advanced fuel ARIES-III design will need a reflectivity of $97 \%$. This would require a first wall coating of either $\mathrm{W}$ or Be. However, a thick W coating can lead to high induced radioactivity and possibly high $\mathrm{Z}_{\mathrm{eff}}$ in the plasma. A Be coating, due to its low melting point, can result in low first wall and coolant operating temperature. Either of these effects would nullify the 
advantage of using a $\mathrm{SiC}$ composite material which combines the desired characteristic of low activation and high temperature operation. Because of this, the organic coolant ferritic steel design was selected as the reference first wall shield design for ARIES-III.

With the selection of the second stability physics and organic coolant for the ARIES-III reactor design, the ARIES team then could work on the system details. GA was in charge of coordinating the divertor system design. The divertor was designed to withstand a maximum heat flux of $5 \mathrm{MW} / \mathrm{m}^{2}$. Based on this modest value of maximum divertor heat flux, the conventional divertor design was selected as the reference design. Sub-cooled flow boiling of the organic coolant will be needed to remove the high surface heat flux. To achieve the goal of having a design safety factor of 2 while maintaining a high coolant outlet temperature, W-Re alloy was selected as the divertor structural material.

\subsection{ARIES-II AND IV DESIGNS}

After the completion of the ARIES-III design, we continued to work on the ARIES-II and ARIES-IV designs. We evaluated different blanket design options. A lithium self-cooled blanket was selected for the ARIES-II design, and a helium-cooled, $\mathrm{SiC}$-composite, $\mathrm{Li}_{2} \mathrm{O}$ solid breeder blanket was selected for the ARIES-IV design. The differences in the ARIES-IV design when compared to the ARIES-I design are the replacement of the $\mathrm{Li}_{2} \mathrm{ZrO}_{3}$ solid breeder by $\mathrm{Li}_{2} \mathrm{O}$, and the elimination of the use of $\mathrm{Be}$ as the neutron multiplier and $\mathrm{W}$ as the divertor protective layer.

Based on the micro-fin heat transfer design approach, we completed the CAD layout of a helium-cooled SiC-composite divertor for the ARIES-IV design. A surface loading of $5 \mathrm{MW} / \mathrm{m}^{2}$ can be removed with acceptable pumping power and this capability can be further improved. The divertor surface is composed of cells $2 \mathrm{~cm}$ in diameter and $15 \mathrm{~cm}$ in length. The design is configured so that it can be fabricated using SiC-composite material. The specifications of this divertor design were chosen to complement the ARIES-IV blanket design which uses helium as the coolant and a SiC-composite as the structural material. The schematics of the ARIES-IV helium-cooled divertor design are presented in Figs. 2.3-1 to 2.3-3.

We reviewed the safety design goals for the ARIES-II lithium self-cooled concept. We recommended that the TITAN safety design approach should be applied to this concept. The ARIES-II reactor should be designed for a level of safety assurance (LSA) rating of 2 . The ARIES-IV reactor should aim for an LSA rating of 1. 


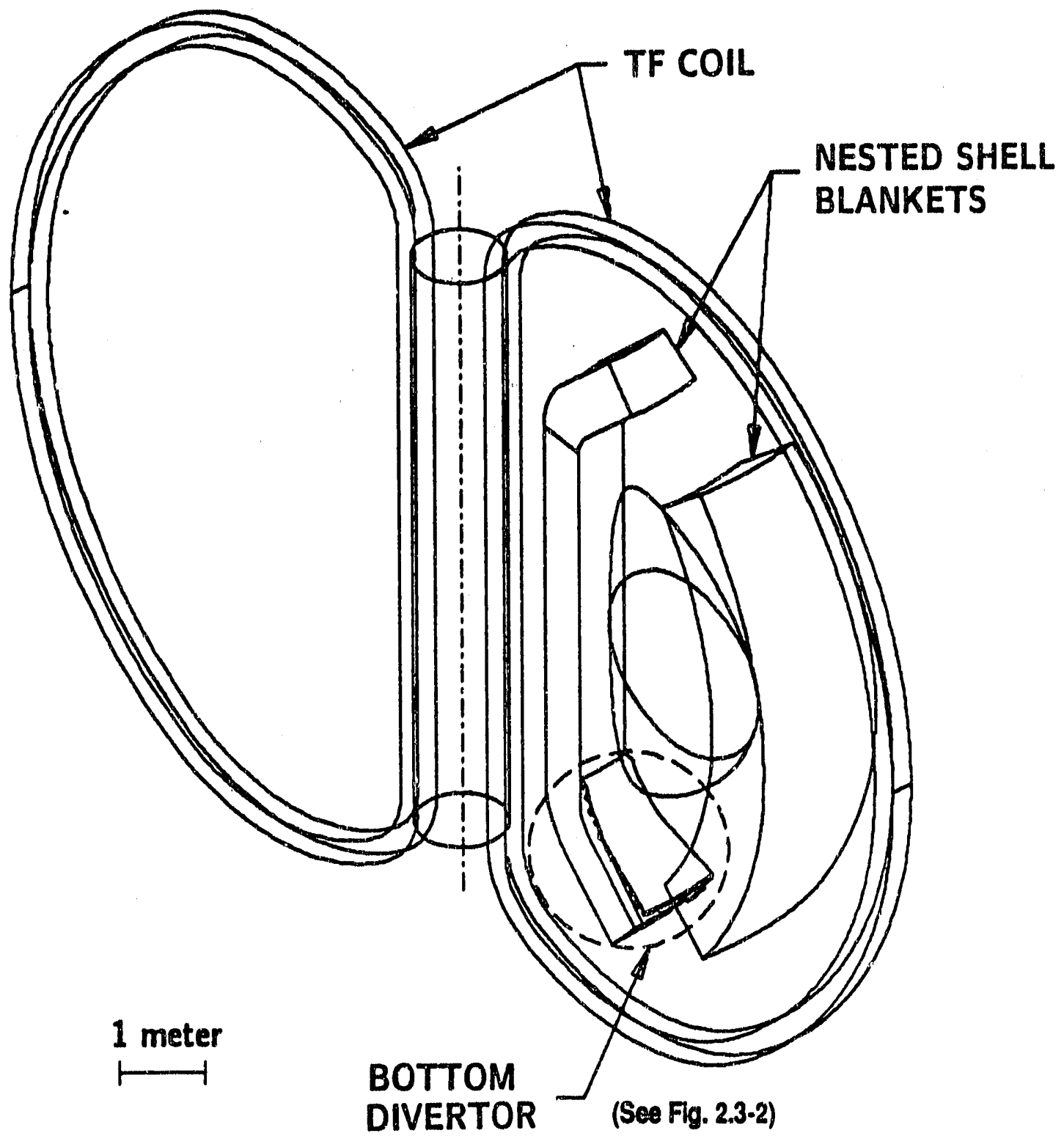

Fig. 2.3-1. Divertor and blanket sector. 


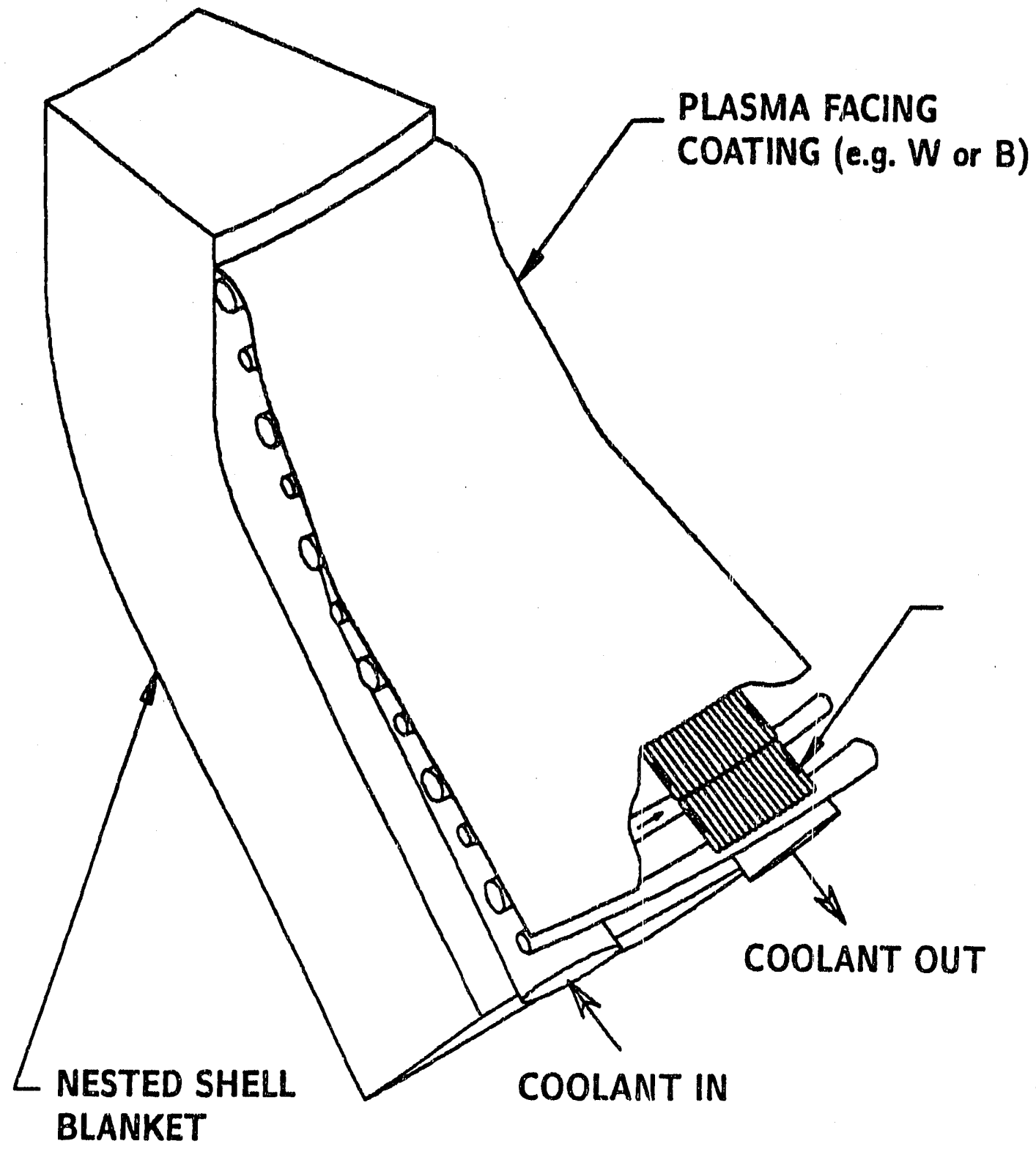

Fig. 2.3-2. He-cooled SiC-composite seciol' details. 

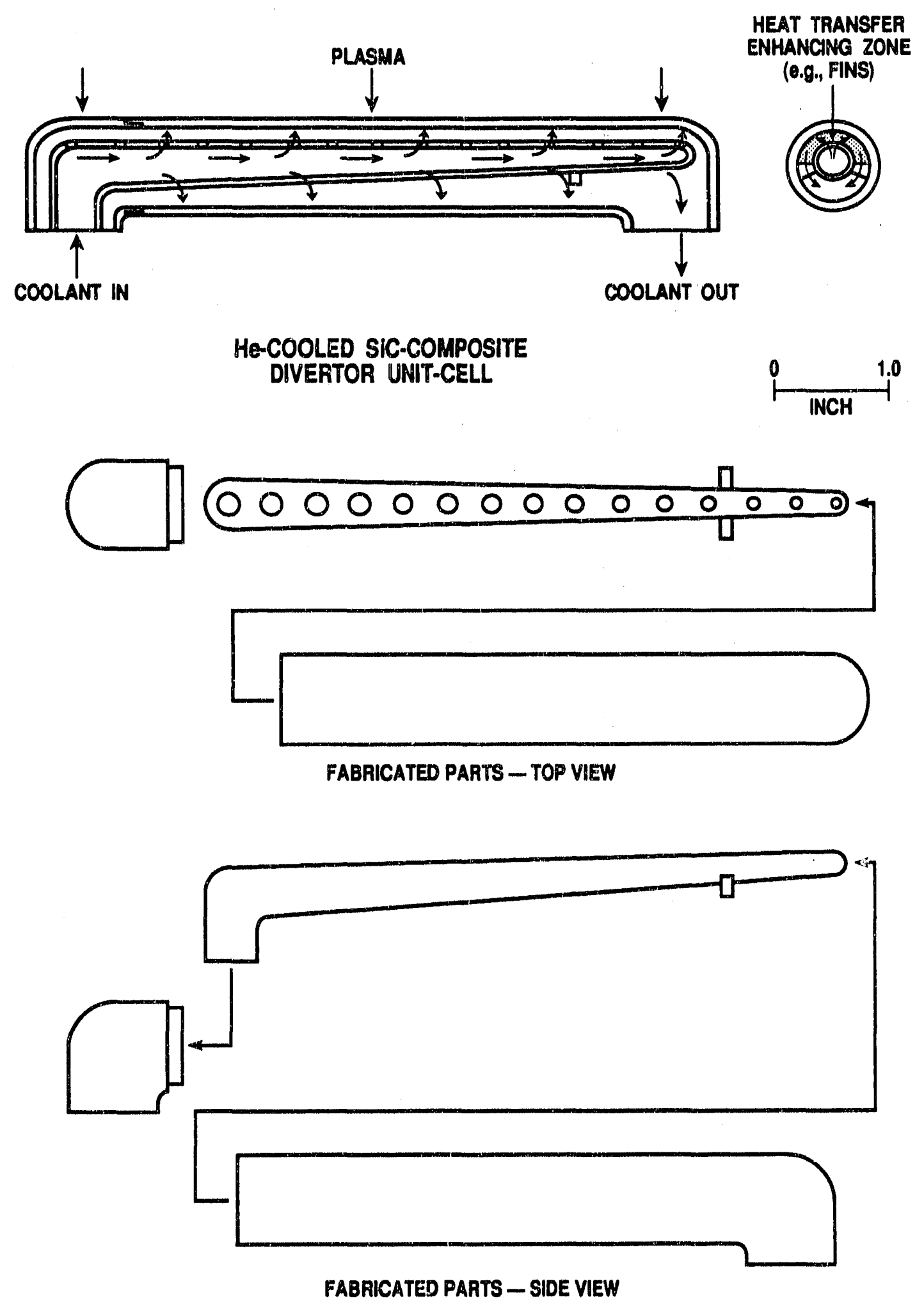

Fig. 2.3-3. He-cooled SiC-composite divertor unit-cell. 


\subsubsection{NEUTRONICS}

For the ARIES-III neutronics design, Edward Cheng identified three issues which needed to be addressed. These issues are: 1. Gamma ray heating of the superconducting magnet and the necessary use of $\mathrm{Pb} ; 2$. Tritium production and inventory in ${ }^{11} \mathrm{~B}$; and 3 . Consistent metallic and ceramic shield design comparison, based on the common design criterion of the neutron fluence design limit of $10^{19} \mathrm{n} / \mathrm{cm}^{2}$.

Design optimization was performed for the ARIES-III helium-cooled SiC-composite inboard shield design. It was found that in order to meet the fluence design limit of $10^{19} \mathrm{n} / \mathrm{cm}^{2}$, the minimum inboard first wall+shield+plenum+vacuum vessel total thickness had to be $95 \mathrm{~cm}$, which is thicker than the $70 \mathrm{~cm}$ organic coolant ferric steel design. This means that the SiC design would have a higher cost of electricity (COE) than the ferritic steel design.

With the selection of the organic coolant and ferritic steel design, we evaluated the activation and afterheat design impact of the W-coated, organic coolant-cooled, ferritic steel divertor design.

To assess material recycling, a study of contact dose rate contributed by the impurity elements for the vanadium alloy lithium self-cooled blanket design was conducted. Concentration limits of natural elements in different zones of the blanket and shield that meet $1 \mathrm{mR}$ per hour and shallow land burial dose limits were identified. These results can be used as a design guide for the costing study of impurity control.

\subsubsection{PHYSICS}

P. Parks supported the ARIES-III design by evaluating the possibility of using ion cyclotron resonance heating at the plasma edge for helium ash removal. The concept is to trap the helium ash in the existing toroidal field ripples so that it can drift out of the plasma and into the divertor chamber where it is pumped out.

M. Chu pointed out that for the ARIES-II and IV reactor designs, there may be a suitable operational regime between the first and second stability regimes. This potentially can lead to a reasonable toroidal Beta, a bootstrap fraction of unity, minimum need for external current drive, a respectable confinement time and a design that is based on moderate extrapolation from present day physics data. $M$. Chu recommended that this in-between first and second stability regime should be explored for the ARIES-II and IV design. 
We also worked with ORNL to bench mark the equilibrium calculation of the DIII-D $11 \%$ Beta experimental results. 
SECTION 3

\section{RF TECHNOLOGY}




\section{RF TECHNOLOGY}

FY91 was mainly a year of experiments with the ICRF System. ICRF is one of the principal candidates for plasma heating and current drive to be used in heating experiments on tokamaks and, ultimately, on reactors.

This year was spent gaining experience with the operation of the Varian EIMAC tetrode (X2274) in the equipment.

Through a cooperative program, ORNL and DOE D\&T have each provided a a fast wave current drive (FWCD) antenna for DIII-D. FWCD experiments have been conducted this year with good results, including some evidence of minority heating. Direct heating of the electrons and some evidence of non-inductive current drive have also been observed. These results were achieved with 1.7 megawatts of RF power. Efforts are continuing to better understand these experimental results and to improve the output from the ICH system at higher power.

Also within FY91 GA coordinated two U.S./Japan RF technology exchanges. The first was in February and was held at the Naka Fusion Research Establishment in Japan. There were five U.S. fusion facilities represented and approximately 45 Japanese representatives from throughout the fusion community in Japan. This was the the first time that there was such significant participation by the Ministry of Education (MOE) so it was a much better exchange than previous ones. Discussions about an ICH collaboration between ORNL and JAERI initiated at this meeting are still ongoing.

The second U.S./Japan RF technology exchange took place in October in conjunction with the IEEE meeting held in San Diego. Japanese representatives from both MOE and Science Technology Agency (STA) and several observers from U.S. labs and the European community participated. There was mutual accord that the exchange benefitted all parties and there is the desire to put together a mutual testing program of high voltage ICRF feedthroughs for the community between GA and JAERI. 


\section{FUSION NUCLEAR TECHNOLOGIES}

GA continued to coordinate the fusion nuclear data needs activities and to represent the fusion neutronics community to the U.S. Nuclear Data Committee, Cross Section Evaluation Working Group (CSEWG), and other nuclear data meetings. The nuclear data needs and status for the development of fusion reactor technology were reviewed. While the general nuclear data status has been improved due to the dedicated effort of data developers during the past two decades, there are still deficiencies in the nuclear data base. These deficiencies occur primarily in the areas of activation and scattering cross-sections. Activation cross-sections were not satisfactory in 83 of the 153 reactions reviewed. The scattering cross-sections for fluorine and boron will need to be improved at energies above $1 \mathrm{MeV}$.

GA continued to lead the coordination activities for the neutron muitiplication integral experiment on beryllium involving U.S., Japan, and USSR. An IAEA-sponsored Advisory Group Meeting was held in Chengdu, China, in December, 1990 to discuss the status of the beryllium neutron multiplication integral experiment. The combined U.S./China beryllium sphere was shipped to Osaka University in Japan. Integral experiments with this combined sphere were conducted there, and analysis is under way. Shipment of the combined beryllium sphere to Kurchatov Institute of Atomic Energy in Moscow, USSR is being arranged for the next series of integral experiments in FY1992. 
SECTION 5

PLASMA FACING COMPONENTS 


\section{PLASMA FACING COMPONENTS}

\subsection{OVERVIEW}

The most challenging conditions to be dealt with by fusion technology occur at the interface between the fusion plasma and the fusion machine. Material erosion of the divertor target materials by physical and chemical sputtering processes is a central issue for high-power, long-pulse divertor tokamaks such as the proposed ITER. In the ITER-CDA design study, the ability to develop divertor plates that survive over extended periods of plasma operation stands out as the most critical technology issue.

ITER R\&D program PH 1.5 has been initiated in response to the need to understand the interaction between the plasma and different divertor surface materials. Material erosion, tritium retention, disruption effects and material transport are very important topics for the design of ITER. We are using DIII-D as a test bed to cirectly measure and model the erosion/ redeposition characteristics of the graphite divertor plates and other phenomena of plasma and material interaction.

\subsection{PROJECT DIRECTIONS}

This project is being carried out as a cooperative effort by a team from SNL-L (material characterization), LLNL (edge plasma measurements and analysis), and GA (project coordination, experimental operations, experiment hardware, and analysis). Erosion/ redeposition analysis is being done in conjunction with SNLA and ANL. GA will perform experiments in DIII-D to measure erosion/redeposition of divertor target materials and other phenomena of plasma and material interaction, and compare experimental results to analytic model predictions.

The project is divided into two phases. In the first phase, 12 divertor tiles were exposed to the divertor plasma from March to December of 1989. The integrated net erosion/ redeposition was determined by accurate profiling of the tile surface and comparison to predicted behavior. A Divertor Materials Evaluation System (DIMES) sample was also exposed 
in DIII-D for a period of five months in FY90. The second phase, which was initiated in FY90, involves the design, fabrication, and installation of the DIMES and the real-time measurements of the erosion during a plasma discharge. The motorized sample changer mechanism will be installed in FY92 and the ellipsometry in situ measurement system will be installed in FY93.

\subsection{INTEGRAL EXPOSURE EXPERIMENT}

From March 29 to December 15, 1989, we exposed 12 well-characterized bottom divertor tiles in DIII-D. DIII-D Confinement, Stability and Transition (CS\&T) data base was reviewed. Out of a total of 4682 . records, approximately 1400 were high power H-mode diverted plasma shots that can have significant impact on the bottom divertor tile erosion. These shots were studied and a strike point distribution was put together and provided as input for the REDEP modeling calculation at ANL. Net erosion of the tiles was measured at SNL-L. It was found that the magnitude of net erosion was comparable between measured and modeled results, yet the distribution of erosion was not well matched. This possibly was due to the plasma events that had happened during the exposed period which were more complicated than the relatively simple plasma model used in the code calculation.

For the second integral experiment, a DIMES graphite sample that had a ${ }^{13} \mathrm{C}$ coating applied to a spot $0.8 \mathrm{~cm}$ in diameter was exposed to the DIII-D experiments for 5 months. The distribution of the ${ }^{13} \mathrm{C}$ isotope was measured and correlated with the plasma conditions at the bottom divertor. Details of the ${ }^{13} \mathrm{C}$ distribution on the DIMES sample is being studied at SNL.

\subsection{DIMES SAMPLE CHANGER SYSTEM.}

In FY91, in order to put together a reliable sample changer design, we evaluated in detail five different design options. A bellows and hydraulics cylinder design was selected and the final DIII-D design review was completed. The bellows will be able to separate the motorized moving parts from high machire vacuum. The sample changer mechanism is expected to be installed in DIII-D in spring, 1992. The DIMES sample has a cylindrical geometry, a diameter of $4.25 \mathrm{~cm}$ and a height of about $7.3 \mathrm{~cm}$. The mechanical design goal is to allow insertion of instrumented samples into the divertor plate region of DIII-D without venting the tokamak. Allowances are being made for as many as 12 electrical leads to be connected from the sample to external instruments. With the sample changer installed, different material samples can be exchanged overnight after only one plasma shot of exposure. Techniques of ellipsometry and 
thin foil measurements for the in-situ measurement of material erosion and redeposition are being developed at SNL-L.

In order to create a portfolio of DIMES experiments for execution in FY92, a request for input was distributed to the community of fusion materials experimentalists. More than 20 suggestions for experiments were received. The planning for FY92 DIMES experiments has been initiated.

\subsection{VISITING SCIENTIST}

In accordance with the US/USSR exchange item II.7, Dr. Irina Opimach of Troitsk, Moscow, spent a month at General Atomics. She participated in the DIMES sample changer design and evaluation. She brought with her three $\mathrm{B}_{4} \mathrm{C}$-coated DIMES samples. These samples will be exposed to DIII-D plasma when the DIMES changer system is operational. The erosion behavior of these $\mathrm{B}_{4} \mathrm{C}$ coated samples will be compared with uncoated graphite samples. 


\section{SECTION 6}

\section{FY91 PUBLICATIONS}




\section{FY91 PUBLICATIONS}

Wong, C.P.C., et al., "ARIES-III Divertor Engineering Design," in Proc. 14th Symp. on Fusion Engineering, IEEE, San Diego, California (1991) (to be published).

Wong, C.P.C., et al., "The Evolution of US Helium-Cooled Blankets," in Proc. 2 nd Int. Symp. on Fusion Nuclear Technology ISFNT-2, Karlsruhe, FRG (1991).

Wong, C.P.C., et al., "ARIES-I SiC Composite Low Activation Blanket Design," Fusion Technology, 19, 3, 2B, FUSTE8, 938 (1991). 


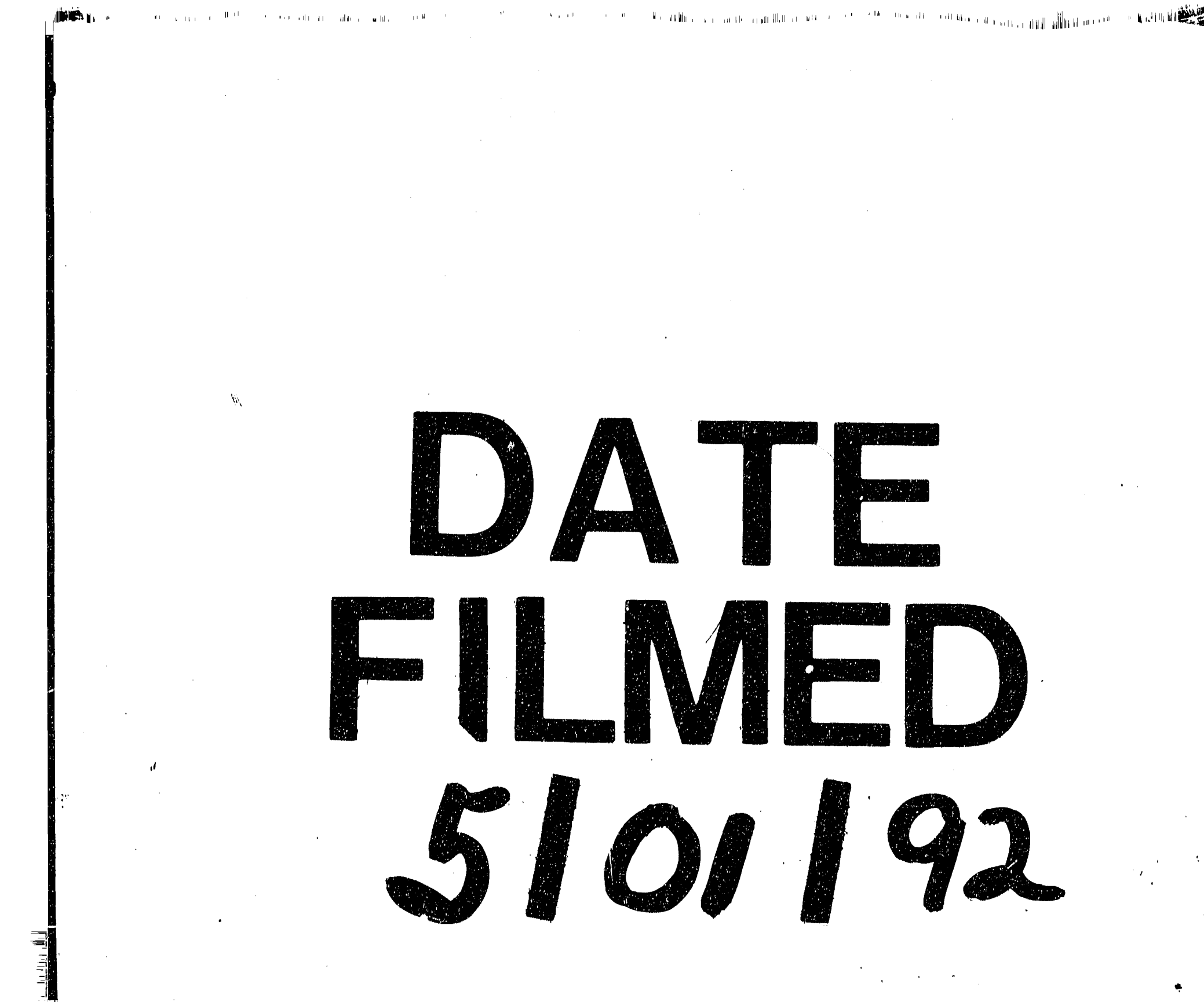




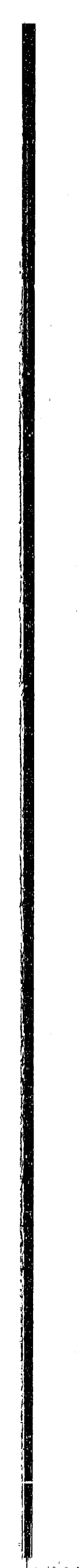

